\title{
A MODERNIDADE CAPITALISTA E O PAPEL DA EDUCAÇÃO
}

\section{LA MODERNIDAD CAPITALISTA Y EL PAPEL DE LA EDUCACIÓN}

\section{CAPITALIST MODERNITY AND THE ROLE OF EDUCATION}

DOI: $\underline{\text { http://dx.doi.org/10.9771/gmed.v11i1.28272 }}$

Aline Maestre Polido ${ }^{1}$

Fátima Aparecida de Souza Francioli²

Resumo: Este artigo se constituiu a partir de estudos bibliográficos com o objetivo de elucidar como se estrutura a sociedade capitalista numa perspectiva materialista histórica, buscando esclarecer a transformação da atividade vital do homem, o trabalho, em uma atividade alienada e alienante, caracterizada pela perca de sentido do trabalho que deveria proporcionar a auto realização humano genérica. Diante dessa problemática procuramos apontar o importante papel da educação como ferramenta que pode auxiliar na superação do processo da alienação diante da modernidade capitalista.

Palavras-chave: Sociedade capitalista. Trabalho. Alienação. Educação.

Resumen: Este artículo se constituyó a partir de estudios bibliográficos con el objetivo de elucidar cómo se estructura la sociedad capitalista en una perspectiva materialista histórica, buscando aclarar la transformación de la actividad vital del hombre, el trabajo, en una actividad alienada y alienante, caracterizada por la pérdida de sentido del trabajo que debería proporcionar la auto realización humano genérica. Delante de esa problemática buscamos apuntar el importante papel de la educación como herramienta que puede auxiliar en la superación del proceso de la alienación delante de la modernidad capitalista.

Palabras clave: Sociedad capitalista. Trabajo. Alienación. Educación.

Abstract: This study was based on bibliographical studies aimed at elucidating how capitalist society is structured in a historical materialist perspective, seeking to clarify the transformation of the vital activity of man, work, into an alienated and alienating activity, characterized by the loss of meaning of the work that should provide for generic human self-realization. Faced with this problem, we sought to point out the important role of education as a tool that can help in overcoming the process of alienation in the face of capitalist modernity.

Key words: Capitalist society. Work. Alienation. Education.

\section{Introdução}

Vivemos atualmente o modo de produção capitalista que visa atender as demandas da mundialização do capital, nesse sentido, o trabalho vem se transformando ao longo do tempo para atender as necessidades que configuram as estruturas capitalistas como diz Souza (2010, p. 142):

[...] a nova cultura empresarial tem buscado construir na classe trabalhadora talvez a mais importante de todas as competências no atual estágio de desenvolvimento do capital: a capacidade para assimilar e aceitar de forma positiva as mudanças que se impõem ao trabalhador no contexto do processo de trabalho e de produção.

Para compreendermos o problema que atinge o mundo do trabalho na modernidade capitalista, partimos do pressuposto de que será necessário situá-lo historicamente na perspectiva do materialismo histórico, pois entender como acontece a dinâmica de nossa atual organização social permite compreender 
como essa dinâmica (modo de produção) influencia diretamente o modo de vida das pessoas, nas formas de reprodução social, propriamente ditas.

\section{Mecanismos da Produção Capitalista}

Para compreendermos os mecanismos da produção capitalista, segundo Marx (2003), é necessário primeiramente entendermos a concepção de homem. Para ele, o conteúdo da essência humana reside no trabalho. Isso significa que na perspectiva marxista, o homem se difere dos outros animais, pois ele não se adapta à natureza como os demais, ao contrário, ele age sobre ela, transformando-a para melhor atender às suas necessidades. Para Marx (2003), essa ação de transformar a natureza, para suprir suas necessidades, é denominada de "trabalho". Portanto, o homem é um ser pensante que, por meio do seu trabalho, modifica a natureza, de maneira que possa viver mais confortavelmente. Nesse sentido, numa visão marxiana, o trabalho é a essência humana, a atividade vital fundante do sujeito ontogenérico.

Conceituando o trabalho, Marx (2003, p. 116) afirma que

Certamente, o trabalho, a atividade vital, a vida produtiva, aparece agora para o homem como o único meio que satisfaz uma necessidade, a de manter a existência física. A vida produtiva, entretanto, é a vida genérica. É a vida criando vida. No tipo de atividade vital está todo o caráter de uma espécie, o seu caráter genérico; e a atividade livre consciente constitui o caráter genérico do homem. A vida revela-se simplesmente como meio de vida.

Sobre essa questão, Lombardi e Saviani (2008, p. 225) assim caracterizam o processo do trabalho humano:

[...] o ser do homem, a sua existência, não é dada pela natureza, mas é produzida pelos próprios homens. Deixado a si mesmo, submetido ao jugo da natureza, o homem perece. Diferentemente dos outros animais que têm sua existência garantida pela natureza bastando-lhes adaptar-se a ela para sobreviver, o homem necessita fazer o contrário. Precisa agir sobre a natureza transformando-a e ajustando-a às suas necessidades. Em lugar de adaptar-se á natureza, tem de adaptá-la a si. E esse ato de agir sobre a natureza transformando-a é o que se chama trabalho. Portanto, é pelo trabalho que os homens produzem a si mesmos. Logo o que o homem é, o é pelo trabalho. O trabalho é, pois, a essência humana.

Ao modificar a natureza pelo trabalho, o homem produz sua própria humanidade, e a ação do trabalho permite que o homem se diferencie e se distancie gradativamente das demais espécies animais. Essa transformação da natureza pelo homem nunca cessa e, assim, ao longo da história, de acordo com Duarte (1999), o homem vai se autocriando, humanizando-se, construindo as características que o definem como humano, ou seja, vai se constituindo enquanto ser social complexo na perspectiva de formação do sujeito ontogenérico.

Ao citar Marx, Duarte (1999, p. 74) trata sobre a autoconstrução do gênero humano e a ação do homem sobre a natureza:

Para Marx, o ponto de partida fundamental a partir do qual se realiza a autoconstrução do gênero humano é a apropriação da natureza pela atividade objetivadora humana. Nesse processo o gênero humano se desenvolve objetivamente e os indivíduos, ao agirem mediados pelas objetivações, tornam-se seres genéricos. O indivíduo faz-se consciente, de si mesmo e do fato de pertencer ao gênero humano, através do mundo criado pelo ser 
humano, do mundo humanizado, do mundo constituído pelas objetivações da atividade humana.

Portanto, para Duarte (1999), a formação do indivíduo genérico, enquanto representante do gênero humano, se realiza na relação entre os processos de apropriação das forças essenciais humanas, utilizadas histórica e socialmente na objetivação do seu desenvolvimento.

A partir do trabalho, o homem transforma a natureza, buscando atender às necessidades essencialmente humanas. Esse processo de transformação é contínuo, portanto, histórico e social, já que o trabalho passa a atender às necessidades humanas coletivas e não mais somente às de um indivíduo, constituindo, assim, o gênero humano.

Para Heller (1970, p. 21):

Também enquanto indivíduo, portanto, é o homem um ser genérico, já que é produto e expressão de suas relações sociais, herdeiro e preservador do desenvolvimento humano; mas o representante do humano-genérico não é jamais um homem sozinho, mas sempre a integração (tribo, demos, estamento, classe, nação, humanidade) - bem como, frequentemente, várias integrações - cuja parte consciente é o homem e na qual se forma sua 'consciência' sobre nós.

Essa passagem da autora esclarece que o ser genérico é também o homem enquanto indivíduo, pois este é representante de suas relações sociais, de modo que o representante do humano-genérico nunca deve ser um homem sozinho, mas sempre o indivíduo integrado à coletividade. Dialeticamente, a vida coletiva não anula as potencialidades individuais, ao contrário, é nela que se efetivam as potencialidades e o desenvolvimento pleno das individualidades.

Porém, com a consolidação da sociedade capitalista, o trabalho como atividade essencialmente humana, perde seu sentido e passa a ser uma ação que visa à manutenção da organização capitalista e não mais atender às necessidades da genericidade humana. O homem não reconhece mais as suas objetivações como objetividade de seu ser genérico e não se enxerga mais enquanto humano, no mundo que os próprios homens construíram, sentindo-se impotente diante de uma realidade que parece dirigida por forças não humanas.

Para Duarte (1999, p. 76), a perda de sentido da atividade vital do homem, a favor das necessidades essencialmente genéricas, acontece "porque o desenvolvimento da genericidade humana tem se realizado através da divisão social do trabalho e da propriedade privada”, resultando na denominada alienação. Ou seja, no mundo do trabalho alienado requer-se a ínfima parte das potencialidades dos homens que vivem da venda da sua força de trabalho, bloqueando o livre desenvolvimento do sujeito humano genérico.

Um aspecto importante para compreendermos a estrutura moderna capitalista é o conceito de propriedade privada:

A propriedade agrária é a primeira forma de propriedade privada, e a indústria surge historicamente após ela, apenas como forma particular de propriedade privada que se lhe opõe - ou melhor, como o escravo liberto na propriedade agrária; tal sequência repetese no estudo científico da essência subjetiva da propriedade privada, do trabalho, e o trabalho começa por aparecer como simples trabalho agrícola, mas em seguida afirma-se como o trabalho em geral.

Toda riqueza se tornou riqueza industrial, a riqueza do trabalho e da indústria é o trabalho realizado, assim como o sistema industrial é a forma objetiva realizada da propriedade privada (MARX, 2003, p. 134). 
Segundo Bottomore (2001, p. 304), "Marx e Engels sustentavam que são as transformações das formas de propriedade que basicamente caracterizam a sucessão das formações econômicas e sociais". A propriedade privada definiu o modo de organização social na Antiguidade, no Feudalismo e no Capitalismo. Ou seja, a propriedade privada diz respeito aos bens materiais que o indivíduo possui e a sociedade organizase de modo a manter e a apoderar-se desses bens.

Porém, para Marx (2003), esse conceito de propriedade privada foi o que fundamentou a origem da desigualdade social na modernidade, para ele, o trabalho deveria ser a propriedade privada do homem como atividade que o realizasse e que atendesse às suas necessidades genéricas.

A essência subjetiva da propriedade privada, a propriedade privada como atividade para si própria, como sujeito, como pessoa, é o trabalho. É claro, portanto, que só a economia política, que reconhecia o trabalho como seu princípio (Adam Smith) e já não jugava a propriedade privada como simples condição externa ao homem, se pode considerar ao mesmo tempo como um produto da energia real e do movimento da propriedade privada, como um produto da indústria moderna e uma força que acelerou e intensificou o dinamismo e o desenvolvimento da indústria, até fazer deste um poder da consciência (MARX, 2003, p. 131).

$\mathrm{Na}$ forma de organização social capitalista, propriedade privada diz respeito aos meios de produção e aos bens de consumo móveis e imóveis que pertencem a determinadas pessoas. Nesse sentido, na busca para a manutenção dos que possuem propriedade privada, bem como para aqueles que querem alcançá-la, ocorre o processo social de alienação sistêmica, inclusive dos capitalistas que lutam para manter e ampliar sua propriedade. Com isso, o trabalho que deveria ser a essência humana passa a ser uma atividade alienada e alienante.

Essa atividade alienada na qual o trabalho se transformou diz respeito

As condições criadas pela divisão do trabalho e pela propriedade privada que introduziram um 'estranhamento' entre o trabalhador e o trabalho, uma vez que o produto do trabalho, antes mesmo de o homem se realizar, pertence a outra pessoa que não o trabalhador. Por isso, em lugar de realizar-se no seu trabalho, o ser humano se aliena nele; em lugar de reconhecer-se em suas próprias criações, o ser humano se sente ameaçado por elas; em lugar de libertar-se, acaba enrolado em novas opressões (KONDER, 2008, p. 30, grifos do autor).

Portanto, para Marx (2003), a propriedade privada perdeu sua essência e passou a significar bens de consumo materiais que movem os indivíduos, de forma alienada, a buscarem cada vez mais a posse de tais bens, alimentando, por meio do trabalho, o cerne principal do capitalismo, que é a geração de capital e não a satisfação das necessidades humanas. $\mathrm{O}$ trabalho passa a estar a serviço da conquista da propriedade privada, nutrindo a finalidade do capitalismo (gerar capital para sua própria continuidade) e não atendendo às reais necessidades do homem enquanto ser social.

$\mathrm{Na}$ forma de organização social capitalista, as necessidades humanas essenciais desaparecem e a vida dos homens passa a ser regida no objetivo de manutenção desse sistema cujo fim é a geração de capital.

Nas palavras de Marx (2003, p. 149),

Cada homem especula sobre a maneira como criar no outro uma nova necessidade para o forçar a novo sacrifício, o colocar em nova dependência, para o atrair a uma nova espécie de prazer e, dessa forma, à destruição. Cada qual procura impor sobre os outros um poder estranho, de modo a encontrar assim a satisfação da própria necessidade egoísta. [...] O homem torna-se cada vez mais pobre como homem, necessita cada vez mais de dinheiro, para poder tomar posse do ser hostil. O poder de seu dinheiro enfraquece em dimensão oposta à massa da produção, ou seja, a sua necessidade aumenta na medida em que cresce o poder do dinheiro. [...] A propriedade privada não sabe 
transformar a necessidade básica em necessidade humana; o seu idealismo é a ilusão, o capricho, a extravagância.

Dessa forma acontece a alienação na sociedade capitalista. Isto é, a propriedade privada faz com que o consumo seja sempre nutrido, gerando nos indivíduos a necessidade de possuir produtos supérfluos, que não são essencialmente necessários a eles. Esse consumismo desenfreado alimenta o sistema capitalista, fazendo com que a produção cresça, aumentando consequentemente a exploração do trabalho.

É assim que o capital impõe a sua dinâmica própria a toda a reprodução social. Em um polo, como estruturador de um mercado mundial e, em outro polo, como estruturador da vida cotidiana de cada um de nós. [...] O capital de hoje tem apenas uma utilidade: comprar mais força de trabalho (diretamente ou indiretamente, quando compra meios de produção) para aumentar a mais-valia e, assim, acumular mais capital num movimento que se repete incessantemente. Assim, o modo de produção capitalista lança a humanidade em um período de desenvolvimento das forças produtivas inédito em toda a história (LESSA; TONET, 2011, p. 65).

O termo alienação, na modernidade capitalista, portanto, deve ser entendido como o processo de embrutecimento do homem, processo que transforma seu trabalho, sua atividade vital em um trabalho no qual ele não se reconhece, causando um estranhamento social, conforme explicam Lombardi e Saviani (2008, p. 226).

[...] consiste no não reconhecimento, pelo homem, de si mesmo seja em seus produtos, seja em sua atividade, seja, ainda, nos outros homens: a) os produtos de seu próprio trabalho são vistos como objetos estranhos, alheios; b) o trabalho, apesar de ser sua própria atividade, é considerado como algo externo ao qual ele encontra não a sua realização, mas a sua perdição, um fator de sofrimento, e não de satisfação; c) em relação aos outros homens, o trabalho alienado torna cada homem alienado por outros os quais, por sua vez, são alienados da vida humana. [...]. Com efeito, objetivamente o trabalho alienado, ao mesmo tempo em que produz mercadorias, produz também o próprio operário como mercadoria.

Dessa forma, a perda da essência do trabalho ocorre pela forma de organização capitalista, e as estruturas sociais, próprias desse modo de produção, nos submetem a uma realidade cotidiana que nos afasta das necessidades tipicamente humano-genéricas, colocando-nos a serviço das exigências do modo de produção da modernidade capitalista. Assim, buscamos nos realizar enquanto indivíduos, lutando para nos enquadrarmos numa posição social favorável e nos esquecemos das necessidades da genericidade humana. Esse antagonismo entre particularidade e genericidade caracteriza, de fato, a alienação.

De acordo com Lessa (2012, p. 150, 151):

A processualidade social global, em seu próprio movimento historicamente determinado, cotidiano, coloca o gênero humano diante de alternativas que o forçam a escolher entre as necessidades, interesses e valores humano-genéricos e as necessidades, interesses e valores apenas particulares. Nas sociedades de classe, essas opções normalmente se colocam sob a forma do predomínio do interesse de uma classe sobre os interesses da totalidade social.

Diante do exposto, foi possível compreendermos como o trabalho, que deveria ser a atividade genérica do homem, perde seu sentido e passa a ser realizado para atender não mais às necessidades humanas, mas às necessidades individuais do homem que luta para sobreviver na estrutura capitalista na qual está inserido. Para melhor compreensão da perda de sentido da atividade vital do homem, em seguida, trataremos sobre como o trabalho vem se configurando no modo de produção capitalista contemporâneo e, o papel da educação na superação da alienação. 


\section{A Alienação e o Papel da Educação}

Após o entendimento do que é o processo de alienação, é importante ressaltarmos que esse processo ocorre na vida dos indivíduos de forma natural, pois nascemos inseridos nesse contexto e moldamos nossas vidas buscando nos adaptar à realidade em que vivemos. Heller (1970, p. 37) fala que a alienação do homem ocorre inconscientemente, ou seja, "a vida cotidiana, de todas as esferas da realidade é aquela que mais se presta à alienação".

Sobre a vida cotidiana, ela esclarece que:

A vida cotidiana é a vida de todo homem. [...] é a vida do homem inteiro, ou seja, o homem participa da vida cotidiana com todos os aspectos de sua individualidade, de sua personalidade. Nela, colocam-se 'em funcionamento' todos os seus sentidos, todas as suas capacidades intelectuais, suas habilidades manipulativas, seus sentimentos, paixões, ideias, ideologias. [...] O homem da cotidianidade é atuante e fruidor, ativo e receptivo, mas não tem nem tempo nem possibilidade de se absorver inteiramente em nenhum desses aspectos; por isso, não pode aguçá-los em toda sua intensidade (HELLER, 1970, p. 17, 18).

A vida cotidiana consiste naquela na qual o homem é submetido, a partir de seu nascimento, a uma estrutura social que está consolidada e, ao nascer, ele passa a se adaptar a tal estrutura (no caso a capitalista) sem refletir sobre ela, passando a realizar as atividades cotidianas com as quais vai se deparando e vai vivendo na espontaneidade, sem reflexão sobre os aspectos cotidianos da vida na sociedade capitalista.

Sobre o processo de alienação na vida cotidiana, Duarte (1999, p. 196) assinala que:

O indivíduo em-si alienado não conduz a vida cotidiana, mas é por ela conduzido. Assume como 'natural' a hierarquia espontânea das atividades cotidianas que encontra pronta em seu meio social imediato, hierarquia essa determinada pelas relações sociais, desde as relações de produção, até as relações mais imediatamente relacionadas à sua posição no quadro das relações alienadas [...].

Isso demonstra que o homem age pela espontaneidade, de acordo com as exigências da estrutura capitalista, assim, ocorre o distanciamento entre o indivíduo e o humano genérico. Cada vez mais o indivíduo passa a agir no mundo inconscientemente, segundo suas particularidades, em detrimento da genericidade humana.

Para Heller (1970), a forma característica da inteira vida seria a união do genérico e do particular, porém já nascemos na cotidianidade e, ao nascer, assumimos dadas funções da vida cotidiana à qual somos submetidos e os choques entre o que é particular e o que é genérico tornam-se inconscientes na vida cotidiana. Desse modo, a particularidade acaba por submeter a si o humano-genérico, colocando as necessidades e interesses sociais a serviço dos afetos, desejos e egoísmo do indivíduo.

Dessa forma, inconscientemente, em nossa vida cotidiana, inserida na forma de organização capitalista, nos distanciamos do humano genérico e passamos a atender às nossas necessidades particulares de forma que possamos viver bem no mundo, sem preocupação com os demais indivíduos. Assim, vivenciamos uma luta pessoal pela sobrevivência, em que cada um é por si. A competitividade toma conta do nosso agir e devemos nos sobressair dos demais, para alcançar melhores condições de vida social.

Ainda, segundo Heller (1970), o moderno desenvolvimento capitalista exacerbou ao extremo a contradição entre o desenvolvimento individual humano e o desenvolvimento humano genérico, de modo 
que cada vez mais os indivíduos buscam atender às suas necessidades efêmeras e particulares em detrimento das necessidades humano-genéricas. Ela afirma que

Existe alienação quando ocorre um abismo entre o desenvolvimento humano-genérico e as possibilidades de desenvolvimento dos indivíduos humanos, entre a produção humano-genérica e a participação consciente do indivíduo nessa produção (HELLER, 1970, p. 38).

Para a autora, a alienação deve ser abolida e superada para que seja possível a "condução da vida" que não significa o fim da hierarquia espontânea da cotidianidade, mas, sim, a coexistência entre particularidade e genericidade, no sentido de que o indivíduo, consciente a partir da moral, obtenha a concepção de mundo, aspirando à autorrealização e refletindo também em realização humano-genérica.

Heller (1970) aponta que, diante da necessidade de controlar os anseios particulares, a ética (moral) surge para conduzir exigências e normas, dirigindo o indivíduo a fim de que este submeta sua particularidade ao genérico. A ética ou moral tem a função de inibição e de transformação das aspirações da particularidade individual. Portanto, “[...] quanto mais intensa é a motivação do homem pela moral, isto é, pelo humanogenérico, tanto mais facilmente sua particularidade se elevará (através da moral) à esfera da genericidade" (HELLER, 1970, p. 24). Assim, é superado o antagonismo entre particularidade e genericidade, podendo o homem decidir, elevando-se acima da cotidianidade.

Sobre o retorno do homem no sentido da genericidade humana, Lessa (2012, p. 151) aponta que:

Para que as necessidades genéricas se tornem operantes na cotidianidade é preciso identificá-las, plasmá-las em formas sociais que sejam visíveis nas mais diversas situações. Valores como justiça, igualdade, liberdade etc. surgem como expressões concretas, historicamente determinadas, das necessidades genérico-coletivas postas pelo desenvolvimento da sociabilidade. Por serem expressões concretas, históricas, das necessidades humano-genéricas, o conteúdo desses valores se altera com o passar do tempo. Se tais mudanças introduzem novos problemas nesse complexo, absolutamente não alteram o fato de tais valores influenciarem decisivamente na identificação das necessidades genéricas e, desse modo, exercerem um papel central na elevação à consciência, em escala social, da contradição singular/universal, gênero/indivíduo.

Para Duarte, a coexistência entre particularidade e genericidade diz respeito à busca do indivíduo para-si e que ele explica da seguinte forma:

O indivíduo para-si é o ser humano cuja individualidade está em permanente busca de se relacionar conscientemente com sua própria vida, com sua individualidade, mediado pela também constante busca de relação consciente com o gênero humano. A dinâmica desse processo é a relação entre objetivação e apropriação, ou seja, o indivíduo se apropria das objetivações genéricas em-si e faz delas mediadoras entre sua consciência individual e as formas pelas quais ele objetiva sua individualidade ao longo de sua vida. Essa individualidade é constante objeto de reapropriação pelo indivíduo para-si, na busca do seu desenvolvimento de forma coerente com a relação que o indivíduo pretende manter entre sua vida e a objetivação do gênero humano (DUARTE, 1999, p. 184-185).

Concluímos, portanto, que, para além da alienação, está a necessidade do desenvolvimento humano, mediado pela ética, pela moral, por valores que induzem o desenvolvimento do indivíduo. Tal desenvolvimento deve ocorrer mutuamente e associado ao desenvolvimento do gênero humano.

Sob esse aspecto, Duarte fala sobre o papel da educação como importante fator que poderá auxiliar na superação da alienação: 
Quando o processo educativo escolar, na sociedade alienada, se limita ao âmbito da genericidade em-si, ele se reduz a satisfazer apenas os carecimentos dos quais o indivíduo se apropriou de forma determinada pela existência alienada. Quando o processo educativo escolar se eleva ao nível da relação consciente com a genericidade, ele cria no indivíduo carecimentos cuja satisfação gera novos carecimentos de nível superior (DUARTE, 1999, p. 189).

Nesse sentido, a educação, em busca da superação da alienação, tem o importante papel no desenvolvimento consciente entre o indivíduo e a genericidade humana, para que seja superada a satisfação das necessidades particulares, promovendo o desenvolvimento do gênero humano.

[...] a prática pedagógica não pode ser concebida apenas enquanto aquela que possibilita ao indivíduo o acesso àquilo que das objetivações genéricas se apresente como imediatamente relacionado aos carecimentos já apropriados pela individualidade, mas sim enquanto aquela que, ao mediar a relação do indivíduo com as objetivações genéricas, gere o carecimento cada vez maior de apropriação dessas objetivações (DUARTE, 1999, p. 190).

De acordo com Duarte (1999), o homem alienado tem sua particularidade como prioridade em detrimento das necessidades do gênero humano, sua vida cotidiana é repleta de conflitos e a causa desses conflitos está na necessidade de ter boa posição no mundo do trabalho. Sua particularidade é, portanto, o centro de seus conflitos.

De forma alienada, passamos a vida lutando para assegurar as condições fundamentais de existência no mundo capitalista. Ao superar a alienação, esses conflitos particulares devem ser superados pela busca da satisfação da necessidade de uma vida humana e não na satisfação das necessidades que derivam da vida alienada.

Ainda sobre o papel da educação para a superação da alienação, Duarte (1999, p. 119) afirma que:

[...] a prática pedagógica tem um papel fundamental na formação do indivíduo, qual seja, o de ser mediadora entre a vivência em-si, espontânea, da genericidade e a condução consciente da vida pela relação também consciente com o processo histórico de objetivação universal e livre do gênero humano.

Ou seja, de acordo com o autor, a prática pedagógica tem o importante papel de elevar a consciência do indivíduo no sentido da genericidade para-si, formando-o de modo consciente sobre a relação de sua vida concreta, histórica e socialmente determinada, e as possibilidades de que suas objetivações estejam a favor do desenvolvimento do gênero humano.

A educação, portanto, deve ser utilizada como ferramenta que possibilita ao indivíduo a superação da alienação por meio da apropriação das objetivações para-si, de modo que, ao se desenvolver como indivíduo, desenvolva-se também como humano genérico mutuamente. Dessa forma, a educação não pode servir apenas para adaptar o indivíduo no mundo capitalista na realidade cotidiana que lhe é imposta, mas que aquela seja um instrumento que permita ao indivíduo compreender as relações que estruturam essa sociedade, suas contradições a fim de buscar a superação da alienação na modernidade capitalista em que vivemos.

\section{Referências}

BOTTOMORE, Tom. Dicionário do pensamento marxista. Rio de Janeiro: Zahar, 2001. 
DUARTE, Newton. A individualidade para si: contribuição a uma teoria histórico-social da formação do indivíduo. 2. ed. Campinas, SP: Autores Associados, 1999.

HELLER, Agnes. O cotidiano e a história. 6. ed. São Paulo: Paz e Terra, 1970.

KONDER, Leandro. O que é dialética. São Paulo: Brasiliense, 2008.

LESSA, Sérgio; TONET, Ivo. Introdução a Filosofia de Marx. 2. ed. São Paulo: Editora Expressão Popular, 2011.

LESSA, Sérgio. Mundo dos homens: trabalho e ser social. 3. ed. São Paulo: Instituto Lukács, 2012.

LOMBARDI, José Claudinei; SAVIANI, Dermeval (Org.). Marxismo e educação: debates contemporâneos. 2. ed. Campinas, SP: Autores Associados, 2008.

MARX, Karl. Manuscritos econômicos filosóficos. São Paulo: Martin Claret, 2003.

SOUZA, José dos Santos. Trabalho, educação e luta de classes na sociabilidade do capital. In: SOUZA; J. dos S.; ARAUJO, R. et al. (Org.). Trabalho, educação e sociabilidade. 1. ed. Maringá: Práxis: Massoni, 2010. p. 133-157.

\footnotetext{
Notas:

${ }^{1}$ Graduação em Pedagogia pela Universidade Estadual do Paraná - UNESPAR/FAFIPA (2011), especialização em Alfabetização Matemática pela Faculdade São Braz (2014), Mestrado em Ensino: Formação Docente Interdisciplinar pela Universidade Estadual do Paraná UNESPAR (2018). Desde 2015 é pedagoga da SEED, atuando em escolas estaduias do Paraná no Núcleo Regional de Educação de Paranavaí. Têm experiência no ensino fundamental I, onde atuou na rede municipal de Paranavaí - PR. Participa do grupo de pesquisa GTPEC - Grupo de Pesquisa Estudo das teorias e práticas pedagógicas na perspectiva crítica da educação escolar. ORCID: Email: alinempolido@hotmail.com

${ }^{2}$ Graduação em Pedagogia com Supervisão Escolar pela Universidade do Oeste Paulista (1996), especialização em Didática pela Associação de Ensino de Marilia (1987), especialização em Formação de Educadores Academicos para EAD pela Universidade federal do Mato Grosso (2003), Mestrado em Educação pela Universidade Estadual de Ponta Grossa (2005) e doutora em Educação Escolar pela UNESP - Campus de Araraquara/SP (2012). Desde 2006 é docente da Universidade Estadual do Paraná - UNESPAR - Campus de Paranavaí, no curso de Pedagogia. Em 2013 ingressou no Programa de Pós-Graduação Stricto Sensu, nível Mestrado Acadêmico em Formação Docente Interdisciplinar - PIPIFOR. Tem experiência na área de Educação, com ênfase em alfabetização, prática de ensino e didática, atuando principalmente nos seguintes temas: formação de professores, trabalho docente, series iniciais do ensino fundamental, metodologias de ensino. ORCID: Email: fas.francioli@hotmail.com
} 